\title{
INFLUENCIA DO USO E MANEJO DO SOLO NOS CÁTIONS TROCAVEIS UM ARGISSOLO VERMELHO
}

\author{
Gustavo Carvalho Garcia ${ }^{1}$
}

\author{
Carolina dos Santos Batista Bonini ${ }^{2}$
}

\begin{abstract}
Alfredo Bonini Neto ${ }^{3}$
\section{RESUMO}

O uso de cobertura vegetal para proteção do solo e aumento do teor de matéria orgânica disponível para as plantas é uma boa alternativa para minimizar os problemas com a perda de qualidade do solo. Neste sentido, o objetivo deste trabalho foi avaliar as propriedades químicas para monitorar a qualidade do solo nos diferentes tipos de manejo. O delineamento experimental utilizado foi inteiramente casualizados, com três tratamentos: Área de vegetação natural; Área de cultivo de cultura perene e Área de pastagem degradada; com 5 repetições. Foram avaliadas as propriedades químicas do solo: teores de potássio, magnésio e cálcio pelo método de extração com resina trocadora de íons. Nas camadas de solo: $0,00-0,10 ; 0,10-0,20$ e $0,20-0,40 \mathrm{~m}$. Os dados foram analisados estatisticamente, utilizando o teste de Tukey a $5 \%$ para comparação das médias. No tratamento sem intervenção humana, houve um acumulo de bases trocáveis, matéria orgânica e fosforo, além da redução da acidez potencial. Os resultados encontrados mostram que o manejo interfere na qualidade química do solo.
\end{abstract}

PALAVRAS-CHAVE: matéria orgânica, acidez do solo, fósforo.

\section{INFLUENCE OF SOIL USE AND MANAGEMENT IN IN EXCHANGEABLE CATIONS OF A ULTISOLS}

\begin{abstract}
The use of vegetal cover to protect the soil and increase the content of organic matter available to plants is a good alternative to minimize the problems with the loss of soil quality. In this sense, the objective of this work was to evaluate the chemical properties to monitor soil quality in different types of management. The experimental design was completely randomized with three treatments: Area of natural vegetation; Area of perennial crop cultivation and degraded pasture area; with five repetitions. Chemical soil properties were evaluated: potassium, magnesium and calcium by extraction with ion exchanger resin. In the soil depths: 0.00-0.10; 0.10-0.20 and 0,20$0,40 \mathrm{~m}$. Data were analyzed statistically using the Tukey test at 5\% for comparison of means. In the treatment without human intervention, there was an accumulation of exchangeable bases, organic matter and phosphorus,
\end{abstract}

\footnotetext{
${ }_{1}^{1}$ Estudante de agronomia, Unicastelo. gustavogarcia.agro@gmail.com

${ }^{2}$ Engenheira Agrônoma, professora assistente doutora na UNESP campus de Dracena. carolbonini@dracena.unesp.br

${ }^{3}$ Matemático, professor assistente doutor na UNESP campus de Tupã. bonini@tupa.unesp.br
} 

the soil.

KEY-WORDS: organic matter, soil acidity, phosphorus.

\title{
INFLUENCIA DEL USO Y MANEJO DEL SUELO EN CATIONES INTERCAMBIABLES DE UN ACRISOLS
}

\begin{abstract}
RESUMEN
El uso de la vegetación para proteger el suelo y aumentar la materia orgánica del suelo disponible para las plantas es una buena alternativa para minimizar los problemas con la pérdida de calidad del suelo. En este sentido, el objetivo de este estudio fue evaluar las propiedades químicas para controlar la calidad del suelo en diferentes tipos de manejo. El diseño experimental fue completamente al azar con tres tratamientos: Área de la vegetación natural; Área de cultivos perennes y zona de pastos degradados; con cinco repeticiones. se evaluaron las propiedades químicas del suelo: El potasio, magnesio y calcio por extracción con resinas de intercambio iónico: En las capas de suelo: 0,00 a 0,10; 0.10-0.20 y 0,20-0,40m. Los datos fueron analizados estadísticamente mediante la prueba de Tukey al 5\% para la comparación de los medios. En el tratamiento sin intervención humana, se produjo una acumulación de bases cambiales y fósforo, materia orgánica, así como la reducción de la acidez potencial. Los resultados muestran que el manejo interfiere con la calidad química del suelo.
\end{abstract}

PALABRAS-CLAVE materia orgánica, acidez del suelo, fósforo.

\section{INTRODUÇÃO}

O uso sustentável dos recursos naturais, especialmente do solo e da água, tem-se constituído em tema de crescente relevância, em razão do aumento das atividades antrópicas. Consequentemente, cresce a preocupação com o uso sustentável e a qualidade desses recursos (Araújo et al., 2007).

A introdução de sistemas agrícolas em substituição às florestas causa um desequilíbrio no ecossistema em que a retirada da cobertura vegetal original e a implantação de culturas, aliadas às práticas de manejo inadequadas, promovem o rompimento do equilíbrio entre o solo e o meio, modificando desta forma, suas propriedades químicas, físicas e biológicas, limitando sua utilização agrícola (Richart, et al., 2005). 
A qualidade desses atributos propicia condições adequadas para o crescimento e o desenvolvimento das plantas e para a manutenção da diversidade de organismos que habitam o solo (Doran \& Parkin, 1994). A avaliação da qualidade do solo de maneira simples e confiável é um dos desafios atuais da pesquisa. Segundo esses autores, ela pode ser medida por meio da quantificação de alguns atributos, ou seja, de propriedades físicas, químicas e biológicas, que possibilitem o monitoramento de mudanças, a médio e longo prazo, no estado de qualidade desse solo.

A qualidade do solo deve ser monitorada para detectar as mudanças que podem ser mediadas em um determinado tempo e pode ser realizadas na propriedade agrícola ou em maior escala, como microbacia hidrográfica, região e outros.

Segundo ARAUJO et al.,(2007), as práticas de manejo e conservação do solo e da água devem ser planejadas e executadas procurando-se manter ou mesmo melhorar seus atributos, de modo a aumentar a capacidade do solo em sustentar uma produtividade biológica competitiva.

Os sistemas de manejo convencionais, especialmente com revolvimento intensivo do solo por meio de aração e gradagem, o que tem favorecido a intensificação dos processos de erosão e compactação do solo e que, em médio e longo prazos, poderá propiciar a degradação física, química e biológica do solo (Leite et al., 2003; Araújo et al., 2004). Nessas condições, a absorção de nutrientes disponíveis pelo sistema radicular é dificultada e a quantidade de oxigênio na rizosfera pode se tornar limitante em diversos processos metabólicos (Beulter \& Centurion, 2004).

ISLAM \& WEIL (2000) propuseram a utilização de dados das características físicas, químicas e biológicas, coletados em solo de uma área de floresta natural não perturbada, como referência para montagem de um índice geral da qualidade do solo.

Segundo BROOKES (1995), a relação entre as propriedades físicos, químicos e biológicos do solo variam no tempo e no espaço. E essas alterações podem ser benéficas ou maléficas aos sistemas de produção. $O$ manejo adequado promove ganho a qualidade do solo e a produtividade das culturas. Diante disso, a variação desses atributos, determinada pelo manejo e uso do solo, e sua avaliação são 
importantes para o melhor manejo visando à sustentabilidade do sistema (Carneiro et al., 2009).

Trabalhos realizados por SOUZA \& ALVES (2003) em Latossolo Vermelho distrófico, mostram que os sistemas de manejo do solo com menor ou nenhum revolvimento do solo levaram a acumulo significativo de matéria orgânica, fosforo, potássio, magnésio e cálcio e diminuição do alumínio trocável e acidez potencial. Já os cultivos com revolvimento o efeito foi o oposto.

Estudos realizados em Latossolo Amarelo, na região norte, no estado do Pará, verificaram que soma de bases e CTC foram as variáveis mais sensíveis a mudanças no manejo (floresta primaria aberta, floresta explorada, pastagem, capoeira, juquira e plantação), e o pH e acidez potencial e $\mathrm{pH}$ do solo foram influenciados pela substituição da floresta por pastagens (Ferreira et al., 2011).

Com isso, o objetivo de avaliar a qualidade química do solo foi estudado as propriedades químicas do Argissolo Vermelho sob diferentes usos e manejo.

\section{MATERIAL E MÉTODOS}

O experimento foi conduzido na área experimental da Fazenda de Ensino e Pesquisa da Universidade Camilo Castelo Branco - UNICASTELO, Campus de Fernandópolis, SP (Fazenda Santa Rita), localizada entre as coordenadas 20¹6'50" latitude sul e $50^{\circ} 17^{\prime} 43^{\prime \prime}$ longitude oeste e $20^{\circ} 18^{\prime} 05^{\prime \prime}$ de latitude sul e $50^{\circ} 16^{\prime} 26^{\prime \prime}$ de longitude oeste (Figura 1). 
Figura 1. Localização da Fazenda Santa Rita, Fernandópolis, SP.

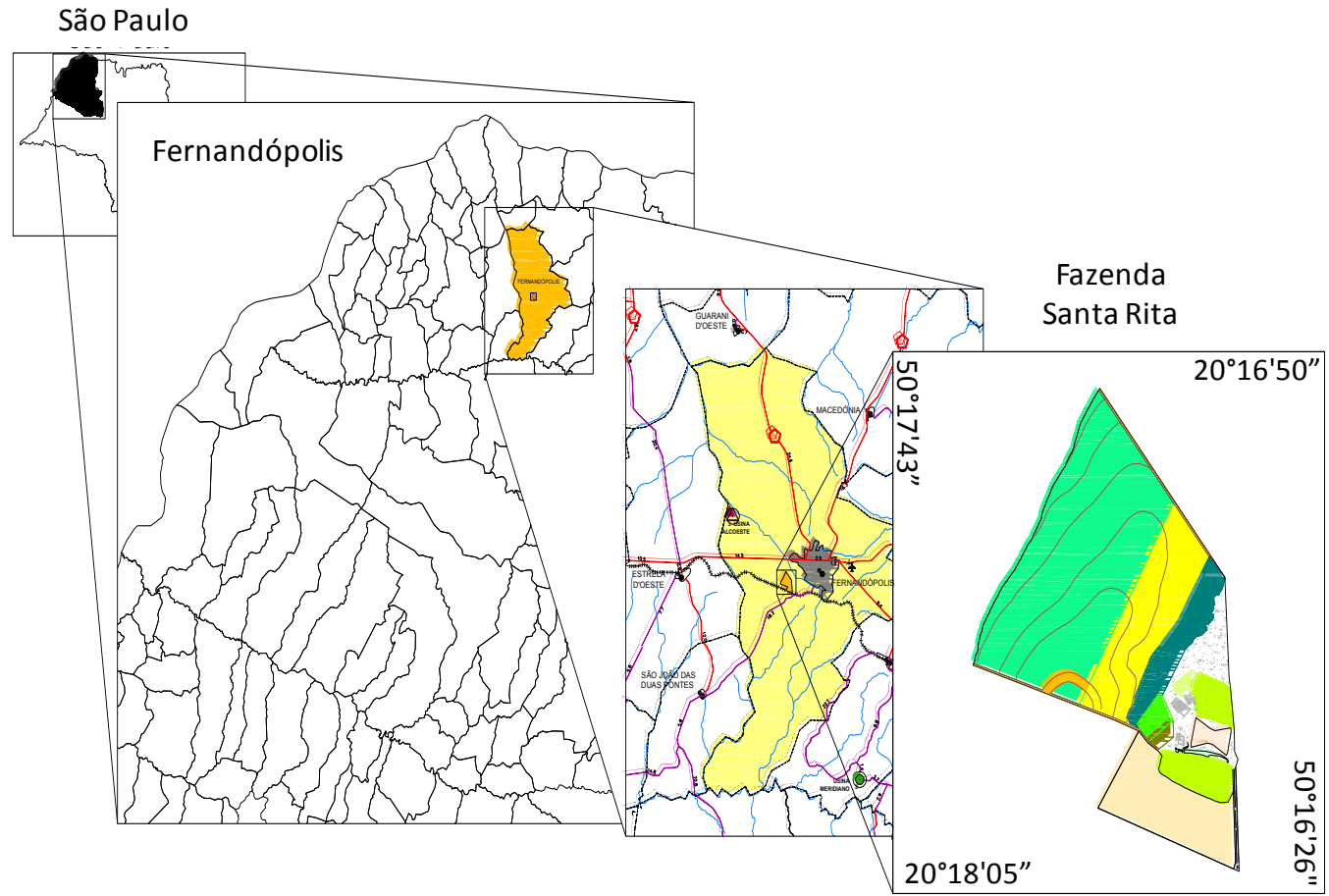

Fonte: AUTOR, 2013.

O clima da região, de acordo com a classificação de Koppen, é subtropical úmido, Aw, com inverno seco e ameno e verão quente e chuvoso (ROLIM et al., 2007). De acordo com a EMBRAPA (2007) a região é caracterizada por um período de 6 meses do ano com déficit hídrico e temperatura média de $23,5^{\circ} \mathrm{C}$ (Tabela 1 ).

De acordo com Oliveira et al. (1999) os solos da Fazenda Santa Rita são constituídos de Argissolos Vermelhos-Amarelos eutróficos abrúpticos A moderado textura arenosa/média relevo suave ondulado e ondulado.

O delineamento experimental adotado será o inteiramente casualizados, sendo 3 tratamentos e 5 repetições, totalizando 25 parcelas experimentais. Sendo os tratamentos:

Área de vegetação natural (Figura 2);

Área de cultivo de cultura perene (implantada há 15 anos, espaçamento $1 \times 2$ m, área sem manejo de adubação) (Figura 2);e

Área de pastagem degradada (3 ha) (Figura 2). 
Para cada tratamento serão utilizadas amostras de solo em duplicatas para uma melhor confiabilidade dos dados.

Tabela 1. Balanço hídrico do município de Fernandópolis, SP.

\begin{tabular}{llllllll}
\hline Mês & $\begin{array}{lllll}\mathrm{T} \\
\left({ }^{\circ} \mathrm{C}\right)\end{array}$ & $\begin{array}{l}\mathrm{P} \\
(\mathrm{mm})\end{array}$ & $\begin{array}{l}\text { ETP } \\
(\mathrm{mm})\end{array}$ & $\begin{array}{l}\text { ARM } \\
(\mathrm{mm})\end{array}$ & $\begin{array}{l}\text { ETR } \\
(\mathrm{mm})\end{array}$ & $\begin{array}{l}\text { DEF } \\
(\mathrm{mm})\end{array}$ & $\begin{array}{l}\text { EXC } \\
(\mathrm{mm})\end{array}$ \\
\hline Jan & 25,2 & 242 & 130 & 100 & 130 & 0 & 84 \\
Fev & 25,3 & 193 & 120 & 100 & 120 & 0 & 73 \\
Mar & 25,0 & 131 & 124 & 100 & 124 & 0 & 7 \\
Abr & 23,4 & 65 & 94 & 74 & 91 & 4 & 0 \\
Mai & 21,2 & 47 & 70 & 59 & 62 & 8 & 0 \\
Jun & 20,2 & 37 & 57 & 48 & 48 & 9 & 0 \\
Jul & 20,1 & 13 & 58 & 31 & 30 & 27 & 0 \\
Ago & 22,3 & 20 & 80 & 17 & 34 & 46 & 0 \\
Set & 24,1 & 35 & 101 & 9 & 43 & 58 & 0 \\
Out & 24,8 & 126 & 119 & 16 & 119 & 0 & 0 \\
Nov & 24,8 & 120 & 120 & 16 & 120 & 0 & 0 \\
Dez & 25,0 & 187 & 131 & 72 & 131 & 0 & 0 \\
\hline Totais & - & 1.216 & 1.205 & 642 & 1.053 & 152 & 163 \\
Médias & 23,5 & - & - & - & - & - & - \\
\hline
\end{tabular}

OBS: $\mathrm{T}$ (temperatura média); $\mathrm{P}$ (precipitação); $\mathrm{ETP}$ (evapotranspiração potencial); $\mathrm{ARM}$ (armazenamento de água no solo); ETR (evapotranspiração real); DEF (deficiência); EXC (excedente). FONTE: EMBRAPA, 2007.

Figura 2. Vista da área experimental

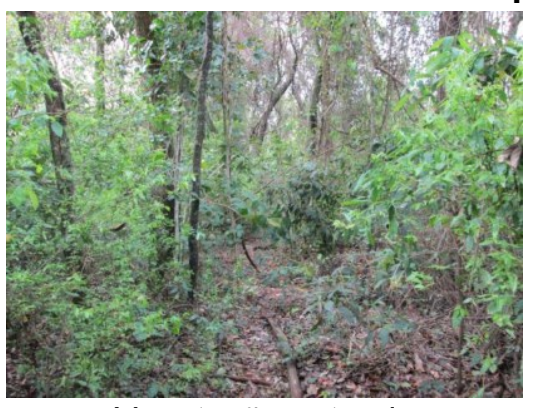

Vegetação natural.

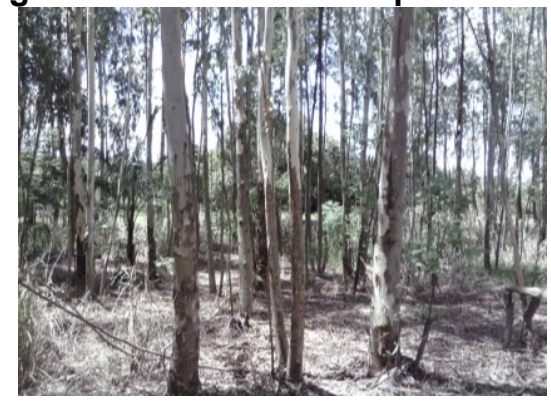

Cultura perene - Eucalipto. Fonte: AUTOR, 2013

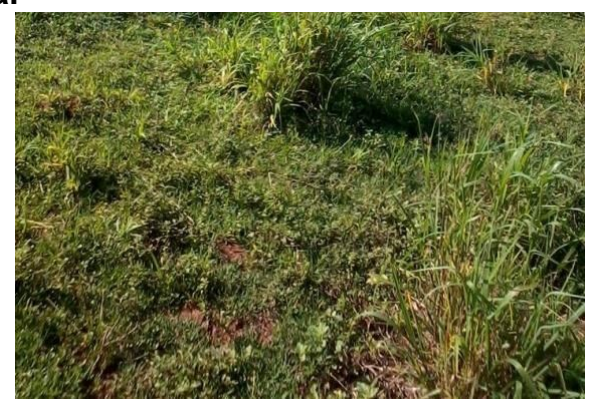

Pastagem degradada

Foram avaliadas as propriedades químicas do solo de acordo com a metodologia descrita por RAIJ \& QUAGGIO (1983) e foram avaliados os teores de potássio, magnésio e cálcio pelo método de extração com resina trocadora de íons. 
As amostras foram coletadas com o auxílio de trado de caneca, em três camadas de solo: $0,00-0,10 ; 0,10-0,20$ e de $0,20-0,40$ m (Figura 3).

Figura 3. Amostra composta de solo que foi utilizado para a determinação da fertilidade do solo e coleta.

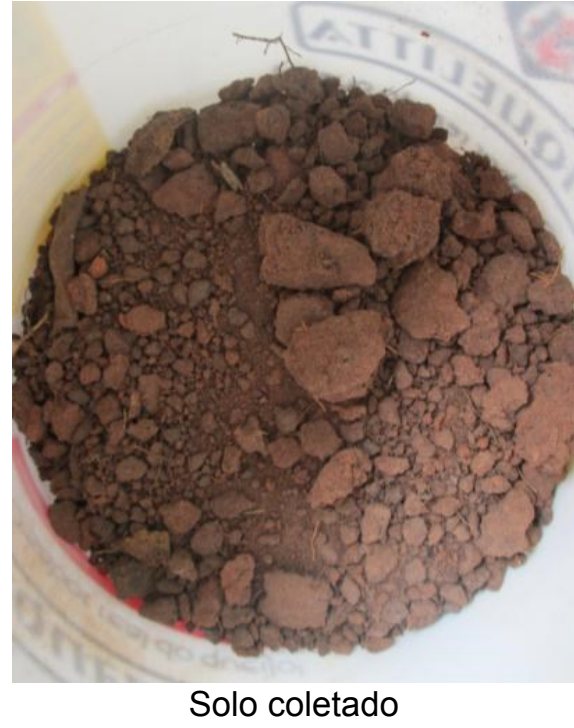

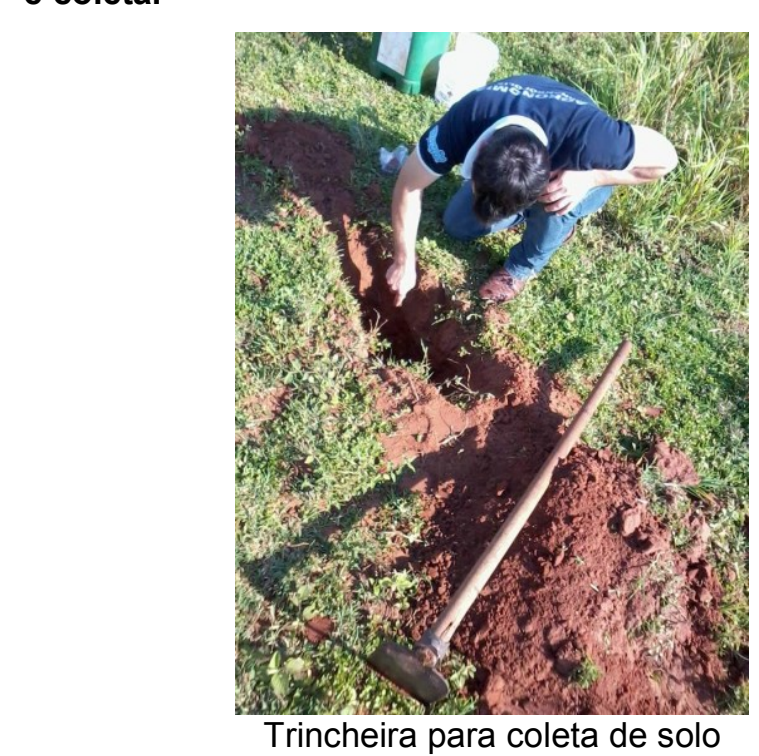

Fonte: AUTOR, 2013.

Para a análise dos dados, foi realizada a análise de variância (teste $F$ ) e aplicou-se o teste de Tukey (5\%), para comparação das médias, utilizando o programa SISVAR (FERREIRA, 2008).

\section{RESULTADOS E DISCUSSÃO}

Os resultados encontrados para as propriedades químicas do solo estão apresentados na Tabela 2 e Figura 4. Para todas as propriedades e camadas de solo estudadas, o teste $\mathrm{F}$ foi significativo a $5 \%$ de probabilidade.

Para o cálcio, potássio e magnésio, os maiores teores encontrados foi para o tratamento vegetação nativa, em todas as camadas estudadas (Figura 4).

Esse maior teor dos nutrientes que são benéficos e essenciais para o desenvolvimento das plantas, foi verificado no tratamento onde não houve 
intervenção humana. Nos tratamentos pastagem e no eucalipto houve uma redução gradativa, isso devido ao maior revolvimento do solo e menor cobertura vegetal.

Segundo Souza \& Alves (2003) que verificaram comportamento semelhante ao encontrado neste trabalho, afirmam que sistemas de manejo com pouco ou nenhum revolvimento de solo, tende a acumular cátions trocáveis, fosforo e matéria orgânica. Também foi verificado o mesmo comportamento em pesquisas realizadas por FERREIRA et al (2011).

Tabela 2: Teste F, DMS (5\%), CV(\%) e valores médios para as propriedades químicas do solo estudadas, nos diferentes usos e manejos do solo, nas camadas de $0,00-0,10 ; 0,10-0,20$ e 0,20 0,40m. 2013.

\begin{tabular}{|c|c|c|c|}
\hline \multirow{2}{*}{ Tratamentos } & $\mathbf{K}$ & $\mathrm{Ca}$ & Mg \\
\hline & \multicolumn{3}{|c|}{$\mathrm{mmolc} \mathrm{dm}^{-3}$} \\
\hline & \multicolumn{3}{|c|}{$0,00-0,10 m$} \\
\hline $\mathrm{F}$ & $16,28^{*}$ & $78,00^{*}$ & $12,92^{*}$ \\
\hline DMS - 5\% & 0,270 & 2,704 & 1,843 \\
\hline \multirow[t]{2}{*}{$\mathrm{CV}(\%)$} & 9,35 & 10,69 & 18,21 \\
\hline & \multicolumn{3}{|c|}{$0,10-0,20 \mathrm{~m}$} \\
\hline $\mathrm{F}$ & $15,97^{*}$ & $166,50^{*}$ & $72,00^{*}$ \\
\hline DMS - 5\% & 0,237 & 1,770 & 1,022 \\
\hline \multirow[t]{2}{*}{$\mathrm{CV}(\%)$} & 8,69 & 7,78 & 11,79 \\
\hline & \multicolumn{3}{|c|}{$0,20-0,40 \mathrm{~m}$} \\
\hline$F$ & $35,48^{*}$ & $25,11^{*}$ & $11,19^{*}$ \\
\hline DMS - 5\% & 0,194 & 1,198 & 2,068 \\
\hline $\mathrm{CV}(\%)$ & 7,92 & 5,82 & 26,31 \\
\hline
\end{tabular}

${ }^{*}$ Significativo a 5\%, ${ }^{\text {ns }}$ não significativo. Fonte: autor, 2013 
Figura 4: gráficos dos valores médios para as propriedades químicas do solo estudadas, nos diferentes usos e manejos do solo, nas camadas de 0,00-0,10; 0,10-0,20 e 0,20-0,40m. 2013.
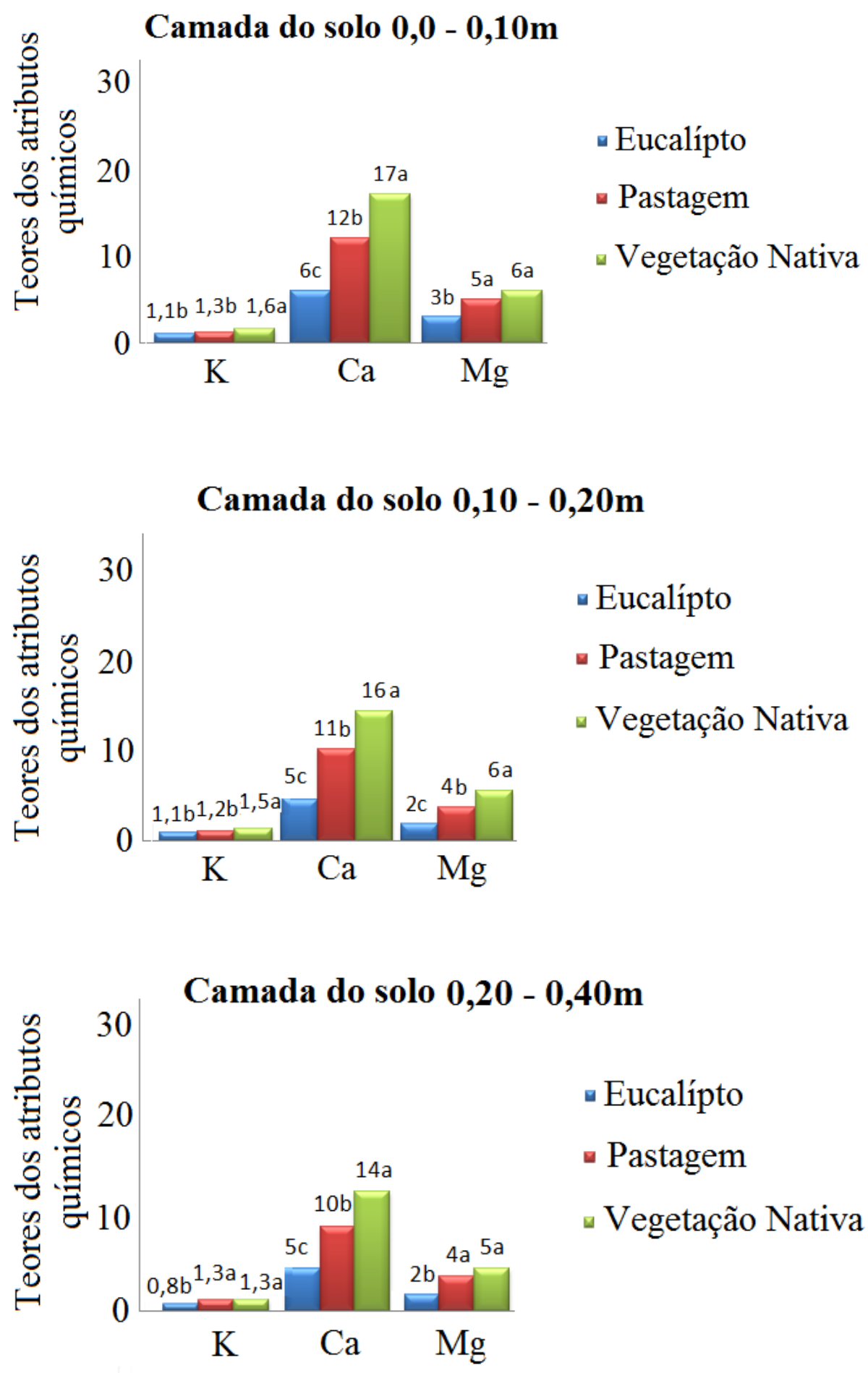

Letras iguais não diferem significativamente para o teste de Tukey (5\%). Fonte: AUTOR, 2013 
Esse acúmulo de bases trocáveis na camada superficial do solo, concorda com uma menor acidez potencial encontrada nos tratamentos vegetação nativa e pastagem. Já para o tratamento eucalipto há uma maior acidez potencial e menor teor de bases trocáveis, fosforo e matéria orgânica do solo. Comportamento idêntico foi verificado por SOUZA \& ALVES (2003) E FERREIRA et al. (2011).

\section{CONCLUSÃO}

As propriedades químicas do solo foram bons indicadores da qualidade do solo.

O tratamento com maior acúmulo de cátions trocáveis foi a vegetação nativa. O pior tratamento foi o eucalipto.

As análises realizadas indicam que o manejo interfere na qualidade química do solo.

\section{AGRADECIMENTOS}

À UNICASTELO - campus Fernandópolis pelo apoio e infraestrutura para realização do trabalho e ao Engenheiro Agrônomo Douglas Costa Martins, pela realização das análises de fertilidade do solo.

\section{REFERÊNCIAS}

ARAÚJO, M.A.; TORMENA, C.A.; SILVA, A.P. Propriedades físicas de um Latossolo Vermelho Distrófico Cultivado e sob Mata Nativa. Revista Brasileira de Ciência do Solo, Viçosa, v. 28, n. 2, p. 337-346, 2004.

ARAÚJO,R.; GOEDERT, W. J. \& MARILUSA, LACERDA, P.C. Qualidade de um solo sob diferentes usos e sob cerrado nativo. R. Bras. Ci. Solo, v. 31, p. 1099-1108, 2007.

BEUTLER, A. N.; CENTURION, J. F. Compactação do solo no desenvolvimento radicular e na produtividade da soja. Pesquisa Agropecuária Brasileira, v.39, n.6, p.581-588, 2004.

BROOKES, P.C. The use of microbial parameters in monitoring soil pollution by heavy metals. Biol. Fert. Soils, v. 19, p. 269-279, 1995. 
CARNEIRO,M.A.C.; SOUZA, E.D.; REIS, E.F.; PEREIRA, H.S. \& AZEVEDO, W.R. Atributos físicos, químicos e biológicos de solo de cerrado sob diferentes sistemas de uso e manejo. $\mathrm{R}$. Bras. Ci. Solo, v.33, p.147-157, 2009.

DORAN, J.W. \& PARKIN, T.B. Defining and assessing soil quality. In: DORAN, J.W. \& COEMAN, D.C.; BEZDICEK, D.F \& STEWART, B.A., eds. Defining soil quality for sustainable environment. Madison, Soil Science Society of America, 1994. p.3-21. (SSSA Special Publication, 35)

EMBRAPA. Banco de dados climáticos do Brasil. Brasília: Embrapa Monitoramento por Satélites, 2007. Disponível em: http://www.bdclima.cnpm.embrapa.br/. Acesso em: 23 nov. 2008.

FERREIRA, D. F.; SISVAR: um programa para análises e ensino de estatística. Revista Symposium, Lavras, v. 6, n. 1, p. 36-41, 2008.

FERREIRA, A N.K.F.; SOUZA, C.M.C.; BASTOS, L.F.; SILVA JUNIIOR, M.L.; MELO, V.S. Propriedades químicas do solo sob diferentes sistemas de uso e manejo em Pacajá (PA). In: anais do $9^{\circ}$ Seminário Anual de Iniciação Cientifica. P.1-4. 2011.

ISLAM, K.R. \& WEIL, R.R. Land use effects on soil quality in a tropical forest ecosystem of Bangladesh. Agric. Ecosys. Environ., 79:9-16, 2000.

LEITE, L. F. C; MENDONÇA, E. S., MACHADO, P. L. O. A., MATOS, E. S. Total C and N storage and organic C pools of a Red-Yellow Podzolic under conventional and no tillage at the Atlantic Forest Zone, Southeastern Brazil. Australian Journal Soil Research, v.41, p.717-730, 2003.

OLIVEIRA, J.B.; CAMARGO, M.N.; ROSSI, M.; CALDERANO FILHO, B. Mapa pedológico do Estado de São Paulo: legenda expandida. Campinas, Instituto Agronômico/EMBRAPA-Solos. Campinas. 1999. 64p.

RAIJ B. V., QUAGGIO J. A. Métodos de análises de solo para fins de fertilidade. Instituto Agronômico de Campinas, 1983. (Boletim técnico n. 81). 31 p.

RICHART, A.; TAVARES FILHO, J.; BRITO, O. R.; LLANILLO, R. F.; FERREIRA, R. Compactação do solo: causas e efeitos Soil compacting: causes and effects. Semina: Ciências Agrárias, Londrina, v. 26, n. 3, p. 321-344, 2005.

ROLIM, G.S.; CAMARGO, M.B.P.; LANIA, D.G.; MORAES, J.F.L. Classificação climática de Köppen e de Thornthwaite e sua aplicabilidade na determinação de zonas agroclimáticas para o estado de São Paulo. Bragantia, v.66, n.4, p.711-720, 2007.

SOUZA, Z.M. \& ALVES, M.C. Propriedades químicas de um Latossolo Vermelho distrófico de Cerrado sob diferentes usos e manejos. Rev. Bras. Ci. Solo, v.27, n.1, p.133-139, 2003. 